\title{
Editor's Note: Citizen Science During the Flint, Michigan Federal Water Emergency: Ethical Dilemmas and Lessons Learned
}

\author{
Rick Bonney
}

This Editor's Note is about the article: Roy, S. and Edwards, M., 2019. Citizen Science During the Flint, Michigan Federal Water Emergency: Ethical Dilemmas and Lessons Learned. Citizen Science: Theory and Practice, 4(1), p. 12. DOI: http://doi.org/10.5334/cstp.154.

\section{Editor's Note}

After publication of Roy and Edwards (2019), Citizen Science: Theory and Practice was contacted by a reader who raised concerns about the clarity of certain data presented in the paper. The data in question appear in this paragraph on page 6 :

"Indeed, by August 2016, CDC revealed alarming statistics that nearly $80 \%$ of Flint residents surveyed from January 21 to April 29, 2016 reported that they had changed their bathing and showering habits including "showering less frequently" (75.3\%), "taking shorter showers" (70.6\%), and bathing in bottled or filtered water (CDC 2016a; Hanrahan 2018). In a follow-up survey of Flint residents that had shigellosis ( $n=24), 52 \%$ reported that they had changed their bathing and showering habits, a much higher percentage than changes in bathing reported in other affected households in Genesee and Saginaw Counties (J. Yoder, Personal Communication, Feb 1, 2018). Top motivating factors for these behavior changes were "media reports" and "health concerns" about bathing (CDC 2016a; CDC 2016b)."

The reader pointed out that the survey of Flint residents described in the article was a survey of only residents who had broken out in a rash. In addition, the reader questioned the derivation of the statistic that $52 \%$ of the Flint residents that had shigellosis had changed their bathing and showering habits. We sent these concerns to the authors, who wrote a response clarifying the statistics presented in the original article. The authors also provided a report from the US Centers of Disease Control (CDC) which presented the findings from the aforementioned survey. We next sent the reader's concerns and the authors' response to two independent reviewers who were not involved in the review of the original article, the topic of the article, or

Cornell Lab of Ornithology, US

rickbonney@cornell.edu as collaborators with any other individual involved in the publication process. These two reviewers stated that after reading all of the material that we provided, they believed that the data, findings, and conclusions of the published article were accurate. However, they also both agreed that the article presented the statistics in this paragraph in a confusing manner, and suggested that clarification be provided.

The authors have rewritten the paragraph to provide clarification, as follows:

Indeed, by August 2016, CDC revealed alarming statistics that nearly $80 \%$ of Flint residents with rashes who were surveyed in a study from January 21 to April 29, $2016(n=371)$ reported that they had changed their bathing and showering habits including "showering less frequently" (75.3\%), "taking shorter showers" (70.6\%), and bathing in bottled or filtered water (CDC 2016a; Hanrahan 2018). The top three motivating factors for the bathing changes (each cited by more than $32 \%$ of respondents) were symptoms, health concerns, and media reports (CDC 2016a). In a follow-up survey of the Flint residents who had shigellosis $(\mathrm{n}=24)$, $52 \%$ reported that they had changed their bathing and showering habits, a much higher percentage than changes in bathing reported in other affected households in Genesee and Saginaw Counties (J. Yoder, Personal Communication, Feb 1, 2018; CDC 2018). Public health officials in Flint stated to national media that "People aren't bathing because they're scared.... People have changed their behavior regarding personal hygiene" (Ganim, 2016), while national reporting headlines stated "Flint residents too scared of the water to wash. That's making them sick' (The Washington Post, Andrews 2016).

We thank the reader for bringing the confusion in the original article to our attention and the authors for providing clarification. 


\section{Competing Interests}

The author has no competing interests to declare.

\section{References}

Andrews, T. 2016. Flint residents too scared of the water to wash. That's making them sick. The Washington Post. Oct 4. Available at: https://www.washingtonpost.com/ news/morning-mix/wp/2016/10/04/flint-residentstoo-scared-of-the-water-to-wash-its-making-them-sick/ (Last accessed 20 January 2018).

Ganim, S. 2016. Amid water crisis, Flint faces a Shigellosis outbreak. CNN. Available at: https://www.cnn. com/2016/10/03/health/flint-water-shigellosis-outbreak/ (Last accessed 6/14/2019).

Hanrahan, J. 2018. Waterborne Diseases. SHEA/CDC Outbreak Response Training Workshop 2018. Available at: http://ortp.shea-online.org/wp-content/
uploads/2018/01/WED_230_Waterborne-Diseases. pdf (Last accessed 24 November 2018).

Roy, S and Edwards, M. 2019. Citizen Science During the Flint, Michigan Federal Water Emergency: Ethical Dilemmas and Lessons Learned. Citizen Science: Theory and Practice, 4(1), p. 12. DOI: http://doi.org/10.5334/cstp.154

U.S. Centers for Disease Control and Prevention (CDC). 2016a. Flint Rash Investigation Report. Aug. Available at: http://www.phe.gov/emergency/events/ Flint/Documents/rash-report.pdf (Last accessed 20 January 2018).

U.S. Centers for Disease Control and Prevention (CDC). 2018. Shigellosis Outbreak in Genesee and Saginaw Counties, Michigan, March 2016 - December 2016. CDC. Available at: http://flintwaterstudy.org/wp-content/ uploads/2019/06/MI_Shigellosis_outbreak_2016_ Report_cleared.pdf (Last accessed 6/14/2019).

How to cite this article: Bonney, R. 2019. Editor's Note: Citizen Science During the Flint, Michigan Federal Water Emergency: Ethical Dilemmas and Lessons Learned. Citizen Science: Theory and Practice, 4(1): 23, pp.1-2. DOl: https://doi.org/10.5334/ cstp.264

Submitted: 12 July 2019 Accepted: 12 July 2019 Published: 02 August 2019

Copyright: (c) 2019 The Author(s). This is an open-access article distributed under the terms of the Creative Commons Attribution 4.0 International License (CC-BY 4.0), which permits unrestricted use, distribution, and reproduction in any medium, provided the original author and source are credited. See https://creativecommons.org/licenses/by/4.0/. 